Felicjan Bylok

Czestochowa University of Technology, Faculty of Management e-mail: byl.f.s@zim.pcz.pl

\title{
Meandry konsumpcji we współczesnym społeczeństwie: konsumpcjonizm versus dekonsumpcja*
}

\section{Meanders in consumption in contemporary society: consumerism versus deconsumption}

The characteristic discriminant of contemporary societies, particularly in economically developed countries, is, on the one hand, the expansion of consumerism in various spheres of economic and social life, while on the other hand, it is the attempt to restrict excessive consumption. The principal aim of this paper is the description of the chosen changes in consumption in contemporary society and their economic consequences. The author searches for answers to the following question: What orientations mark out the behaviour of consumers in the market? In the search for answers to this question, the orientation towards excessive consumption that is stimulated by the ideology of consumerism and deconsumption as a protest against consumerism have been placed under analysis. In analysing the ideology of consumerism, the main styles of consumerism have been indicated as follows: consumption of pleasures, compulsive consumption and symbolic consumption. In contrast to the behaviour associated with over-consumption, the behaviour in pursuit of the restriction of the consumption of goods indirectly connected with actual needs has been described, namely sustainable consumption and anti-consumption, as well as the voluntary simplicity movement in consumption.

Keywords: consumptionism, consumption, sustainable consumption, consumption styles, consumption society

JEL Classification: D11, Z13

\footnotetext{
* Artykuł opublikowany w ramach projektu „Popularyzacja najnowszej wiedzy ekonomicznej wśród ludzi młodych" realizowanego z Narodowym Bankiem Polskim w ramach programu edukacji ekonomicznej.
} 


\section{Uwagi wstępne}

W społeczeństwach kapitalistycznych wysokorozwiniętych zwanych konsumpcyjnymi dominuje orientacja na nabywanie coraz to nowych produktów. Orientację tę wspierają zarówno producenci, którzy zyskują na ciągłym wzroście popytu na nowe produkty, jak i państwo, które czerpie korzyści z podatków od dóbr i usług konsumpcyjnych. Podejmowane są różne działania stymulujące ludzi do zakupów, które przybierają postać przedsięwzięć marketingowych (np. reklama, promocje), jak i rozwiązań finansowych wspomagających sprzedaż, np. mniejszy podatek VAT, dogodniejsze kredyty, itd. Wszystko to prowadzi do rozwoju hiperkonsumpcji. Należy się zatem zgodzić z tezą Z. Baumana, że życie w społeczeństwie konsumpcyjnym polega na ciągłym nabywaniu, spożywaniu, użytkowaniu, pozbywaniu się odpadów, aby następnego dnia rozpocząć wszystko od początku ${ }^{1}$. Konsekwencją tych zachowań jest z jednej strony nadprodukcja dóbr konsumpcyjnych, a z drugiej strony - wzrost zagrożeń ekologicznych.

Wraz z rozwojem hiperkonsumpcji pojawiają się postawy krytyczne wobec niej, wskazujące na zagrożenia związane z jej ekspansją we współczesnym świecie. Upowszechniają się nowe formy zachowania w konsumpcji, m.in. zrównoważona konsumpcja, dobrowolna prostota w konsumpcji (voluntary simpicity), wolniejsze życie (slow life) itd.

Głównym celem opracowania jest refleksja nad współczesną konsumpcją. Autor poszukuje odpowiedzi na pytanie: jakie najważniejsze orientacje wyznaczają zachowania konsumentów na rynku? W związku z tym pytaniem stawia tezę, że dekonsumpcja może stać się trwałym trendem rozwoju współczesnej konsumpcji. W celu weryfikacji postawionej tezy wykorzystana została metoda studiów literaturowych.

\section{Wokól pojęcia konsumpcjonizmu}

Konsumpcjonizm jest pojęciem wielowymiarowym i z tego względu poszczególni jego badacze wskazują na jego różne aspekty. Wykorzystywane jest, po pierwsze, do wyjaśnienia rosnącego znaczenia konsumpcji jako czynnika zmian społecznych $^{2}$, po drugie, do wyjaśnienia nadmiernego konsumowania dóbr, które jest związane $\mathrm{z}$ niezaspokojonym pragnieniem nabywania coraz to nowych dóbr konsumpcyjnych $^{3}$, po trzecie, wiąże się pojęcie konsumpcjonizmu z globalizacją, w szczególności z kulturą globalną ${ }^{4}$, po czwarte, wiąże się konsumpcjonizm z typem układu

\footnotetext{
${ }^{1}$ Z. Bauman, Życie na przemiat, Wyd. Literackie, Kraków 2005.

${ }^{2}$ F. Bylok, Konsumpcja, konsument i społeczeństwo konsumpcyjne we współczesnym świecie. Studium socjologiczne, Wyd. Naukowe „Śląsk”, Katowice 2013.

${ }^{3}$ L. Sklair, Sociology of the global system, Johns Hopkins University Press, Baltimore 1991.

${ }^{4}$ G. Ger, R.W. Belk, I'd Like to Buy the World a Coke: Consumptionscapes of the "Less Affluent World", „Journal of Consumer Policy” 1996, vol. 19, s. 271-304.
} 
społecznego $^{5}$, po piąte, ujmuje się go jako drogowskaz dla życia ludzi ${ }^{6}$. W tych rozumieniach konsumpcjonizm staje się jednym z głównych czynników determinujących funkcjonowanie jednostki we współczesnym społeczeństwie.

Konsumpcjonizm staje się specyficznym sposobem życia, który związany jest z nadmiernym nabywaniem i spożywaniem dóbr. Charakterystycznym wzorem zachowania jest shopping rozumiany dwojako: jako dokonywanie spontanicznych zakupów w centach handlowych, albo jako forma konsumpcji zmysłowej, związana z oglądaniem wystaw i produktów w sklepach bez motywu ich zakupu ${ }^{7}$. W pierwszym rozumieniu może przybrać postać zakupów powiązanych z określonym celem lub bez określonego celu. Zakupy z celem mają utylitarny charakter, dotyczą nabywania dóbr lub usług niezbędnych do zaspokojenia potrzeb, często są postrzegane jako swoista ,praca”. Natomiast zakupy bez określonego celu mają hedonistyczny charakter, w którym przyjemność i zabawa jest najważniejsza. W drugim rozumieniu shopping oznacza doznawanie przyjemności podczas spacerowania i oglądania towarów w sklepach. Konsument idzie pospacerować, posłuchać, powąchać, posmakować, czyli doświadczyć różnych wrażeń wśród eksponatów ze świata marzeń wystawianych w centrach handlowych. Staje się postflaneurem, czyli osobą, która odwiedza sklepy w celu doznawania przyjemności z oglądania wystaw sklepowych $^{8}$.

Ważnym elementem sposobu życia opartego na ciągłej konsumpcji coraz to nowych dóbr jest wykorzystywanie konsumpcji do tworzenia tożsamości indywidualnej. Jak zauważa K-U. Hellmann, konsumpcjonizm jest programem, który ludzie wykorzystują do konstruowania (post)modernistycznej tożsamości wybierając go spośród wielu innych propozycji ${ }^{9}$. Przy czym taka tożsamość nie wyraża się w jednej postaci, ale występuje w wielu różnych odmianach, między którymi nie ma zasadniczych różnic. Jednostka może swobodnie wybierać różne tożsamości w zależności od sytuacji społecznej. Można mówić w tym przypadku o swoistej płynności tożsamości.

Konsumpcjonizm rozumiany jest również jako ideologia społeczeństwa konsumpcyjnego, która ma dostarczać nowych wizji życia dla ludzi. Według R. Bockock konsumpcjonizm jest aktywną ideologią, która sugeruje, że życie opiera się przede wszystkim na kupowaniu rzeczy i przeżywaniu doświadczeń dostarczanych w pakietach z dobrami konsumpcyjnymi. Wskazuje, iż najważniejszym celem dla człowieka staje się konsumpcja ${ }^{10}$. Z kolei L. Sklair uważa, że konsumpcjonizm to ideologia zawierająca zestaw przekonań i wartości powiązany z kapitalistyczną globalizacją, której celem jest przekonanie ludzi, iż szczęście najlepiej

\footnotetext{
${ }^{5}$ Z. Bauman, Konsumowanie życia, Wyd. Uniwersytetu Jagiellońskiego, Kraków 2009.

${ }^{6}$ S. Miles, Consumerism - as a Way of Life, Sage, London 1998.

${ }^{7}$ K-U. Hellman, Das konsumistische Syndrom [w:] Räume des Konsums über den Funktionswandel von Räumlichkeit im Zeitalter des Konsumismus, red. K-U. Hellman, G. Zurstiege, VS Verlag für Sozialwissenschaften, Wiesbaden 2008, s. 36.

${ }^{8}$ W. Wątroba, Homo postmillenius, Wyd. Uniwesytetu Ekonomicznego we Wrocławiu, Wrocław 2008, s. 83 .

${ }^{9}$ K-U. Hellman, op. cit., s. 41.

${ }^{10}$ R. Bockock, Consumption, Routledge, London 1993, s. 48.
} 
osiągnąć poprzez konsumpcję i posiadanie dóbr ${ }^{11}$. Zatem ideologia ta uzasadnia nastawienie prokonsumpcyjne członków społeczeństwa wysokorozwiniętych, jak i rozwijających się. Występując w powiązaniu z globalną kulturą staje się jednym z najważniejszych czynników wywołujących zmiany w życiu społecznym. Jak zauważa S. Miles, konsumpcjonizm podporządkowuje sobie rzesze konsumentów na całym świecie. Przenika on codzienne życie i struktury codziennych doświadczeń ludzi. Poprzez ciągłe zmiany swojej formę staje się atrakcyjny, wzmacniając swój wpływ na ludzi ${ }^{12}$.

C. Bartholomew analizując konsumpcjonizm wyróżnia następujące jego cechy. Po pierwsze, wskazuje na kulturę konsumpcji jako podstawę konsumpcjonizmu, w której wartości związane są z konsumpcją. Po drugie, konsumpcjonizm jest utożsamiany $\mathrm{z}$ indywidualnym wyborem. Wolność wyboru produktu, stylu życia czy własnej tożsamości jest zasadą obowiązującą we współczesnym społeczeństwie konsumpcyjnym. Po trzecie, kultura konsumpcyjna kreuje potrzeby jako nieograniczone i zarazem nienasycone ${ }^{13}$. Konsumpcjonizm oferuje sposoby zaspokojenia tych potrzeb, jednak jak na ironię, ciągle pojawiają się nowe, co powoduje poczucie nienasycenia i zmusza konsumentów do poszukiwań coraz to nowych dóbr konsumpcyjnych.

Siła konsumpcjonizmu tkwi w tym, że dostarcza instrumentów (dóbr konsumpcyjnych i wzorów konsumpcji) służących do tworzenia jednostkowej i zbiorowej tożsamości dla wszystkich jednostek, w każdym czasie i miejscu na świecie. Zaletą tej ideologii jest to, że oferuje nowe formy życia społecznego i formy identyfikacji, które są dostępne powszechnie. Można powiedzieć, że zapewnia złudzenie równości w nierówności, czyli ludzie mają równy dostęp do dóbr konsumpcyjnych, ale nabywać mogą je jedynie ci, którzy posiadają odpowiednie środki finansowe.

\section{Style konsumpcji propagowane przez konsumpcjonizm}

Konsumpcjonizm, pomimo że nie posiada wyraźnie zdefiniowanych celów i ośrodków rozpowszechniania swoich idei, jest ekspansywny. Ta ekspansja przejawia się w propagowaniu różnych stylów konsumpcji, które są atrakcyjne dla ludzi. Do najważniejszych zalicza się m.in. konsumpcję przyjemności, konsumpcję ostentacyjną, konsumpcję symboliczną i konsumpcję spontaniczną. Poniżej podjęto próbę opisu najważniejszych elementów poszczególnych stylów konsumpcji.

\footnotetext{
${ }^{11}$ L. Sklair, Iconic Architecture and the Culture-ideology of Consumerism, ,Theory, Culture \& Society” 2010, vol. 27, nr 5, s. 135.

${ }^{12}$ S. Miles, Consumerism - as a Way of Life, Sage Publications 1td., London 1998, s. 3.

${ }^{13}$ C. Bartholomew, Christ and Consumerism: An Introduction [w:] Christ and Consumerism. Critical reflections on the spirit of our age, red. C. Bartholomew, T. Moritz, Paternoster Publishing, Carlisle 1988, s. 6-9.
} 


\subsection{Konsumpcja przyjemności}

W społeczeństwie konsumpcyjnym dążenie do przeżywania przyjemności stało się jednym z ważnych celów w życiu ludzi. Konsument nie stawia jedynie pytania, jak osiągnąć coś w życiu, lecz pytanie, czego oczekuje od życia. Odpowiedzią jest przyjemne, pełne przygód i niespodzianek życie. G. Schulze szukając odpowiedzi na pytanie o kulturowe uwarunkowania życia człowieka w społeczeństwie dobrobytu wskazuje, że sens życia współczesnego człowieka warunkuje dążenie do przeżywania przyjemności i przygody ${ }^{14}$. Dobra konsumpcyjne z zawartością przyjemności są środkiem realizacji celów życiowych, dzięki nim życie konsumenta nabiera sensu.

Konsekwencją takiego podejścia jest rozwój orientacji na przyjemność, która oznacza, że w akcie zakupu wpływ na decyzje konsumenta mają nie tyle funkcje użytkowe produktu, ale przede wszystkim funkcje symboliczne. Funkcjonalność i rzeczowa jakość z tego punktu widzenia jest ważna, ale niezbędny jest ukryty potencjał zaspakajania potrzeby przyjemności i przygody. Produkty z ukrytą zawartością przyjemności wpływają na subiektywne zadowolenie konsumenta. Zawartość przyjemności w produkcie może stanowić wygląd (design), opakowanie, materiał, z którego jest wykonany, kolor, zapach, itd. Zawartość znaczeniowa jest często powiązana $\mathrm{z}$ wartościami hedonistycznymi, co wpływa na subiektywne odczuwanie przyjemności. Głównym źródłem konsumpcji stymulowanej wartościami hedonistycznymi jest wyimaginowane użycie wymarzonych dóbr. Produkty, które zawierają w sobie potencjał marzeń są najbardziej poszukiwane. Jednakże po ich nabyciu konsument traci zainteresowanie nimi, ponieważ zaczyna marzyć o innych dobrach. C. Campbell thumaczy ten proces za pomocą zmodyfikowanego modelu decyzji konsumenckich: tęsknota - zakup - użycie - rozczarowanie. W modelu tym potrzebę zastąpiono tęsknotą (marzeniem) ${ }^{15}$. Zaspokojenie marzeń jest wyznacznikiem osiągania przyjemności.

Z badań nad zachowaniami konsumpcyjnymi wynika, że konsumenta nastawionego na osiąganie przyjemności cechuje przede wszystkim zachowanie, w którym dominuje poszukiwanie nowości na rynku, osiąganie przyjemności poprzez oglądanie reklamy, wystaw sklepowych i spacerowanie po dużych sklepach oraz poprzez akt kupna. Do grupy konsumentów nastawionych na osiąganie przyjemności zalicza się osoby, które żyją według dewizy „,nowość jest najlepsza”, tj. najlepsze, najbardziej modne wyposażenie jest dobrem najbardziej pożądanym przez tę grupę konsumentów. Konsumpcja i uprawianie sportów są wykorzystywane do tworzenia własnej tożsamości ${ }^{16}$.

Reasumując, wzrost znaczenia orientacji na przyjemność w życiu społecznym oznacza tworzenie się specyficznej zbiorowej mentalności przyjemności, w której doznawanie przyjemności jest ważnym wskaźnikiem jakości życia.

\footnotetext{
${ }^{14}$ G. Schulze, Die Erlebnisgesellschaft. Kultursoziologie der Gegenwart, Verlag Campus, Frankfurt/M 1992.

${ }^{15}$ C. Campbell, The Romantic Ethic and the Spirit of Modern Consumerism, Basil Blackwell Publisher, London 1987, s. 84.

${ }^{16}$ F. Bylok Konsumpcja w Polsce i jej przemiany w okresie transformacji, Wyd. Politechniki Częstochowskiej, Częstochowa 2005, s. 376-378.
} 


\subsection{Konsumpcja ostentacyjna}

We społeczeństwach wysokorozwiniętych większość ludzi nie ma problemów z zaspokojeniem potrzeb podstawowych. Znaczna częśc z nich orientuje się w swoich zachowaniach na poszukiwanie dóbr, które zaspokoją ich potrzeby wtórne, związane z życiem społecznym. Jednym z głównych motywów takiego zachowania jest dążenie do wyróżnienia się spośród innych poprzez demonstrowanie posiadania dóbr uznawanych za społecznie ważne. Ten styl konsumpcji można nazwać konsumpcją ostentacyjną. Po raz pierwszy przejawy tej konsumpcji opisał T. Veblen, który analizując społeczeństwo dziewiętnastowieczne scharakteryzował konsumpcję na pokaz ${ }^{17}$. Wskazał, że konsumpcja jest środkiem do zdobywania prestiżu w klasie wyższej i wśród arystokracji. Aby konsumpcja mogła przynosić uznanie w oczach innych należało pokazać to, co się ma w nadmiarze, czego nie można do końca spożyć, przy czym dobra te musiały być widoczne dla tych, z którymi się porównywano.

We współczesnym społeczeństwie cechą konsumpcji ostentacyjnej jest przesunięcia punktu ciężkości z nabywania i demonstrowania dóbr w stronę doświadczenia i symbolicznego obrazu. Konsumenci już nie chcą podkreślać swojej pozycji poprzez ekstrawagancję i duże wydatki, ale dzięki bardziej subtelnym zachowaniom na rynku. Można za P. Bourdieu powiedzieć, że tym, co wyróżnia człowieka jest gust powiązany z klasą społeczną ${ }^{18}$. Gust jest wskaźnikiem przynależności klasowej, bowiem indywidualne wybory, które opierają się na zasadzie poczucia smaku, są zawsze wariantem praktyk klasowych. Atrybutami gustu są dobra powiązane ze wzorami konsumpcyjnymi, poprzez które konsument komunikuje otoczeniu przynależność do określonej klasy społecznej. Określone układy gustów, upodobania dotyczące konsumpcji oraz praktyki związane ze stylami życia umożliwiają zbudowanie mapy gustów i stylów życia w społeczeństwie, która odpowiada w mniejszym lub większym stopniu podziałowi klasowemu. Dzięki tej mapie można klasyfikować swój gust do określonej klasy, jak i można klasyfikować innych.

Konsumpcja ostentacyjna jest powiązana $z$ efektem snoba. Zostało to po raz pierwszy opisane przez H. Leibensteina, który wskazał, iż konsument pragnący wyróżnić się społecznie przy zakupie dóbr bierze pod uwagę, z jednej strony osobiste i emocjonalne pragnienie posiadania prestiżowych marek, a z drugiej strony decyzja o zakupie podyktowana jest potencjalnym stopniem wrażenia, jaki wywrze ten produkt na innych osobach ${ }^{19}$. Przy czym istotny jest publiczny kontekst demonstrowania produktu. Im większa jest publiczność, tym silniejsza jest chęć kreowania takiego stylu konsumpcji, który wyróżnia jednostkę spośród innych konsumentów.

\footnotetext{
${ }^{17}$ T. Veblen, Teoria klasy próżniaczej, PWN, Warszawa 1971.

${ }^{18}$ P. Bourdieu, Dystynkacja. Spoleczna krytyka władzy sadzenia, Wydawnictwo Naukowe Scholar, Warszawa 2005, s. 237.

${ }^{19}$ H. Leibenstein, Bandwagon, Snob, and Veblen Effects in The Theory of Conspicuous Demand, „Quartely Journal of Economics" 1950, vol. 64, s. 183-207.
} 
Często miejscem do tej prezentacji są różne wydarzenia, np. koncerty, bale charytatywne, przedstawienia teatralne oraz areny konsumpcji (centra czy pasaże handlowe).

Współcześnie konsumpcja na pokaz nadal wywiera istotny wpływ na zachowanie konsumpcyjne, przy czym nie dotyczy jedynie członków klas najwyższych. Ludzie najubożsi również chcą się społecznie wyróżnić, dlatego często ograniczone środki finansowe przeznaczają na dobra luksusowe. K.H. Hörning uważa, że w sytuacji, gdy przy niskich dochodach dochodzi do wysokiego poziomu aspiracji, występuje zjawisko asymetrii stylów wydawania pieniędzy. Osoba chcąc przynależeć do wyższej warstwy, dokonuje więc ,amoralnego przywłaszczenia” sobie dóbr będących symbolami konsumpcji dostępnych dla wyższej warstwy ${ }^{20}$.

Reasumując, w dzisiejszym społeczeństwie można wskazać na dualizm form konsumpcji ostentacyjnej. $Z$ jednej strony obserwuje się rozwój strategii ostentacyjnej konsumpcji z jej dobrami luksusowymi, a z drugiej - strategię dążenia do zewnętrznej ekspresji poprzez indywidualny styl życia. Ludzie chcą poprzez konsumpcję wyrazić swoje ,ja”. Dzięki użyciu dóbr z zawartością symboliczną mogą komunikować własną odrębność innym ludziom.

\subsection{Konsumpcja symboliczna}

Kolejnym stylem propagowanym przez konsumpcjonizm jest konsumpcja symboliczna ukierunkowana na dobra z zawartością symboliczną, czyli takie, które reprezentują określony styl życia pojedynczej osoby czy grupy społecznej lub całego społeczeństwa $^{21}$. Aby dobro konsumpcyjne mogło być uznane za produkt zawierający zawartość symboliczną musi posiadać „widoczność” (visibilät) i ,znaczenie” (signifikant) $^{22}$. „Widoczność” oznacza symbole i znaki szczególnie rzucające się w oczy, natomiast ,znaczenie” to zarówno jednoznaczność wyróżniania, jak i kolektywnie podzielane zdanie na temat danego znaczenia dobra. Widoczność i znaczenie nadają dobrom konsumpcyjnym komunikacyjny charakter. Produkt, aby mógł być uznany za prestiżowy, musi być widoczny i uznany za trwały. Innymi słowy, produkty nie stają się luksusowymi w świadomości społecznej ze względu na ich fizyczne właściwości, lecz ze względu na ich obraz, jaki posiadają w społeczeństwie.

Najczęściej dobra wyposażone w zawartość symboliczną tworzą określony spójny układ symboli, np. styl życia powiązany z rolami społecznymi. Dobra konsumpcyjne posiadające treść symboliczną są zazwyczaj komplementarne wobec siebie. G. McCracken sytuację tę określa jako „Jedność Diderota”. Symboliczne dopasowanie dóbr jest wynikiem powiązań między kulturowymi kategoriami i kategoriami dóbr ${ }^{23}$.

\footnotetext{
${ }^{20}$ K.H. Hörning, Ansätze zu einer Konsumsoziologie, Verlag Rombach, Feiburg 1970.

${ }^{21}$ A. Stihler, Die Entstehung des modernen Konsums. Darstellung und Erklärungsansätze, Verlag Duncker und Humbold, Berlin 1998, s. 204.

${ }^{22} \mathrm{G}$. Wiswede, Konsumsoziologie - Eine vergessene Disziplin [w:] Konsum: soziologische, ökonomische und psychologische Perspektiven, red. D. Rosenkranz, Verlag Leske+Budrich, Opladen 2000, s. 48.

${ }^{23} \mathrm{G}$. McCracken, Culture and Consumption. New Approaches to the Symbolic Character of Consumer Goods and Activities, Indiana University Press, Bloomington/Indianapolis 1988, s. 123.
} 
Konsumpcja symboliczna oznacza nabywanie produktów na podstawie ich wartości symbolicznych, przy czym coraz mniejsze znaczenie mają symbole związane ze statusem społecznym. Rośnie natomiast znaczenie potencjału emocji, jakie posiadają dobra konsumpcyjne. J. Rifkin opisuje ten fenomen jako „kulturowy kapitalizm”, w którym niematerialne dobra, takie jak przeżycia i atmosfera, w sposób widoczny stają się dobrami na sprzedaż ${ }^{24}$. Również G. Schulze wskazuje na rozwój tego zjawiska. Według niemieckiego socjologa ma miejsce przejście od wartości użytkowej i statusowej produktu do wartości emocjonalnych i wartości fikcyjnych $^{25}$. Jest to wynikiem zmiany konsumpcji zorientowanej na zewnątrz w stronę wewnętrznej konsumpcji. Przeżycia, które konsument kupuje, są silnie powiązane z dobrami. Na przykład powstają restauracje, które mają dostarczać przeżyć kulinarnych, kluby oferujące niezwykłe atrakcje, biura turystyczne proponujące wczasy pełne przygód, centra handlowe zapewniające różne formy rozrywki. Wspólną cechą tych przedsięwzięć jest oferta dostarczenia nieznanych dotychczas konsumentowi doświadczeń i niezwykłej atmosfery. W tych miejscach jednostka może realizować swoje fantazje. Niezwykłe przeżycia i niecodzienna atmosfera stają się symbolami konsumpcji nieograniczonej żadnymi barierami.

Reasumując, we współczesnym świecie konsumpcja symboliczna stała się istotnym elementem konsumpcjonizmu stymulując zachowania konsumpcyjne w kierunku nabywania dóbr z zawartością symboliczną i emocji. Konsumenci nie poszukują dóbr jedynie ze względu na ich wartość użytkową, lecz takich, które oferują dodatkowo znaczenie symboliczne, posiadają swoistą etykietę. Celnie opisuje tę sytuację W. Ullrich, który wskazuje, że współczesne rozwinięte społeczeństwo dobrobytu cechuje się przejściem od produkcji dóbr do produkcji wizerunku (obrazu $)^{26}$.

\subsection{Konsumpcja spontaniczna}

Kolejnym stylem propagowanym przez konsumpcjonizmu jest konsumpcja impulsywna, którą cechuje irracjonalność przejawiająca się w spontanicznym nabywaniu dóbr. Impulsywne zakupy różnią się od racjonalnych tym, że decyzje o nabyciu danego produktu podejmowane są szybko, pod wpływem emocji i bez głębszej refleksji. R. Haubl na podstawie badań wysnuł wniosek, że duża część konsumentów dokonuje zakupów pod wpływem impulsu, przy czym paradoksalne „zakupy impulsywne" są zaplanowane, jednakże nie chodzi tutaj o planowanie podejmowane przez konsumenta, lecz o planowanie sprzedawcy ${ }^{27}$. Właściciele sklepów aranżują sytuacje, w których konsumenci tracą kontrolę nad swoimi decyzjami. Stosują w tym celu różne techniki marketingowe np. gratyfikacje, podarunki, oferty rabatowe, itd. Poza tym wykorzystują wystrój sklepu i atrakcyjną muzykę, które mają

\footnotetext{
${ }^{24}$ Cyt. za: W. Ullrich, Habenwollen. Wie funktioniert die Konsumkultur? S. Fischer Verlag, Frankfurt am Main 2006, s. 46.

${ }^{25}$ G. Schulze, op. cit., s. 427.

${ }^{26}$ W. Ullrich, op. cit., s. 45.

${ }^{27}$ R. Haubla, ,Welcome to the pleasure dome” Einkaufen als Zeitvertrieb [w:] Freizeit in der Erlebnisgesellschaft. Amüsement zwischen Selbstverwiwklischung und Kommerz, red. H.A. Hartmann, R. Haubl, Auflag 1, Westdeucher Verlag, Wiesbaden 1996, s. 218.
} 
wytworzyć przyjazną atmosferę sprzyjającą spontanicznym zakupom. M. Prisching uważa, że celem producenta i jego oferty jest wytworzenie u potencjalnego nabywcy stan transu konsumpcyjnego, który polega na tym, że dla konsumenta świat dóbr konsumpcyjnych staje się najważniejszy ${ }^{28}$. Sam akt zakupu staje się dla niego przyjemnością, rozwiązaniem psychologicznego napięcia, spełnieniem marzeń.

Konsumpcja spontaniczna opiera się na orientacji „tu i teraz”. Z badań nad zachowaniami konsumentów na rynku wynika, że konsumenci spontaniczni są to osoby podejmujące decyzje o nabyciu danego artykułu handlowego pod wpływem chwili, bez kontroli swoich wydatków konsumpcyjnych. W przypadku braku gotówki na zakup droższych, bardziej luksusowych rzeczy, zaciągają kredyt lub pożyczają pieniądze od swoich znajomych lub rodziny. Ten typ konsumenta charakteryzuje fascynacja konsumpcją i orientacją „tu i teraz” („obojętnie ile to kosztuje, muszę to mieć"). Wydawanie pieniędzy jest dla nich ważniejsze niż ich zarabianie. Kupują często rzeczy ze względu na ich funkcje symboliczne, nie zwracając natomiast uwagi na ich funkcje użytkowe ${ }^{29}$.

\section{Dekonsumpcja}

We współczesnych społeczeństwach nastawionych na nadmierną konsumpcję, nieadekwatną do rzeczywistych potrzeb, pojawiają się zachowania i postawy ukierunkowane na umiarkowane konsumowanie dóbr i usług. Można mówić w tym przypadku o tworzeniu się nowego trendu w konsumpcji, tzw. dekonsumpcji, która staje się alternatywą wobec konsumpcjonizmu. W literaturze pojęcie to jest różnie definiowane. C. Bywalec i L. Rudnicki określają dekonsumpcję jako świadome ograniczanie konsumpcji do rozmiarów racjonalnych, wynikających z naturalnych, indywidualnych, fizycznych i psychicznych cech konsumenta ${ }^{30}$. Z kolei E. Szulc ujmuje dekonsumpcję jako racjonalną, świadomą, odpowiedzialną i etyczną konsumpcję. Jej hasłem jest „mniej znaczy więcej”31. Dekonsumpcja, zatem związana jest z ograniczeniem dotychczasowej nadmiernej konsumpcji z różnych względów, np. kryzysu ekonomicznego, zmiany stylu życia, wzrostu niepewności, większej świadomości związanej z odpowiedzialnością, podejścia etycznego do konsumpcji itd. Może przyjmować różne formy, takie jak konsumpcja zrównoważona, konsumpcja etyczna, antykonsumpcja, ruchy na rzecz ograniczania konsumpcji np. ruch dobrowolnej prostoty w konsumpcji, powolna konsumpcja (slow consumption) itd. Najczęściej opisywaną formą dekonsumpcji jest konsumpcja zrównoważona. Występują trzy sposoby ujmowania kategorii zrównoważonej konsumpcji: jako alternatywny sposób życia, jako

\footnotetext{
${ }^{28}$ M. Prisching, Die zweidimensionale Gesellschaft. Ein Essay zur neokonsumistischen Geisteshaltung, VS Verlag für Sozialwisenschaft, Wiesbaden 2009, s. 122.

${ }^{29}$ F. Bylok, Konsumpcja w Polsce..., s. 375-376.

${ }^{30}$ C. Bywalec, L. Rudnicki, Konsumpcja, PWE, Warszawa 2002, s. 143.

${ }^{31}$ E. Szulc, Dekonsumpcja-moda czy kryzys, seria: Nierówności społeczne a wzrost gospodarczy, nr 24, Uniwersytet Rzeszowski, Rzeszów 2012, s. 318.
} 
ekokonsumpcja i holistyczne ujęcie zrównoważonej konsumpcji32. Podejście pierwsze zakłada odejście od dotychczasowego sposobu konsumpcji nastawionego przede wszystkim na realizację potrzeb wtórnych. Do najważniejszych założeń tego podejścia można zaliczyć: życie w niewielkich samowystarczalnych wspólnotach, by ograniczyć do minimum koszty środowiskowe związane z transportem, ograniczenie zaspokojenia potrzeb do minimum niezbędnego do życia, podejmowanie działań przeciwko tym, którzy degradują środowisko naturalne. Drugie podejście zakłada, iż najważniejszym celem powinna być konsumpcja ekologiczna (ekokonsumpcja). Konceptualizacja tego pojęcia opiera się na założeniu, że ochrona środowiska naturalnego może być osiągnięta poprzez wzrost popytu na ekologiczne produkty wytwarzane w warunkach przyjaznych środowisku. Kluczem do zrównoważonej konsumpcji z tej perspektywy jest wzrost racjonalnych i świadomych ekologicznych postaw i zachowań opartych na głębokich wartościach ${ }^{33}$. Konsument przy podejmowaniu decyzji o wyborze określonego produktu bierze pod uwagę nie tylko spełnienie osobistych pragnień i satysfakcji, lecz również konsekwencje dla środowiska naturalnego. Jak zauważają R. Harrison, R. Newholm i D. Shaw, podczas nabywania dóbr konsument ekologiczny patrzy nie tyle na siebie, ale przede wszystkim na świat, który go ota$\mathrm{cza}^{34}$. Z kolei trzecie podejście, holistyczne, zakłada, że konsument przy podejmowaniu decyzji o nabyciu określonego produktu uwzględni nie tylko skutki środowiskowe, lecz również skutki społeczne (w tym prawa człowieka, np. sprawiedliwą płacę dla zatrudnionych przy jego wytwarzaniu pracowników), międzypokoleniowe i ekonomiczne. Zmiana zachowań konsumpcyjnych w kierunku zrównoważonej konsumpcji staje się coraz powszechniejsza z uwagi na wzrost świadomości związanej z odpowiedzialnym konsumowaniem.

Ważną rolę w upowszechnianiu idee zrównoważonej konsumpcji odgrywają konsumenckie ruchy społeczne. Do najważniejszych z nich zaliczamy ruchy ekologiczne, które promują konsumpcję proekologiczną. Konsumpcja ekologiczna jest elementem ruchu konsumentów związanym z ekokonsumpcją, którego celem jest zahamowanie negatywnych procesów degradujących środowisko naturalne i pogarszającą się jakość życia człowieka przez zmiany w sferze konsumpcji. Ruch ten postuluje zmiany, które powinny przybrać postać: racjonalnego wykorzystania dóbr konsumpcyjnych; przyjęcia postawy zgodnej z zasadami ochrony środowiska naturalnego; konsumowania dóbr ekologicznych (głównie żywności); ograniczania konsumpcji dóbr, które tworzą groźne odpady pokonsumpcyjne; preferowania w konsumpcji dóbr, które ,wytwarzają” niewielkie ilości odpadów pokonsumpcyjnych; ograniczenia zużycia zasobów i energii do produkcji dóbr konsumpcyjnych oraz minimalizacji zużycia zasobów naturalnych poprzez stosowanie czystych technik wytwarzania dóbr konsumpcyjnych ${ }^{35}$.

\footnotetext{
${ }^{32}$ A. Dąbrowska, F. Bylok, M. Janoś-Kresło, D. Kiełczewski, I. Ozimek I., Kompetencje konsumentów - innowacyjne zachowania, zrównoważona konsumpcja, Wyd. PWE, Warszawa 2015, s. 83-84.

${ }^{33}$ J.A. Ottman, Green Marketing: Challenges and Opportunities for the New Marketing Age, NTC Business Books, Lincolnwood 2003.

${ }^{34}$ R. Harrison, R. Newholm, D. Shaw, Pressure groups, campaigns and consumers [w:] The Ethical Consumer, red. R. Harrison, T. Newholm, D. Shaw, Sage, London 2005, s. 2.

${ }^{35}$ F. Bylok, Konsumpcja, konsument i społeczeństwo konsumpcyjne we wspótczesnym świecie, Wyd. Naukowe Sląsk, Katowice 2013, s. 224-228.
} 
Innym ruchem społecznym, który propaguje idee zrównoważonej konsumpcji jest ruch dobrowolnej prostoty w konsumpcji (Voluntary Simplicity Movement), którego założeniem jest redukcja materialnej konsumpcji i zmiana dotychczasowego stylu życia poprzez ,usunięcie bałaganu z własnego życia” na rzecz stylu życia opartego na prostocie związanej z ograniczeniem nabywania wielu niepotrzebnych dóbr konsumpcyjnych ${ }^{36}$. Generalnie ruch dąży do ograniczenia nabywania dóbr, korzystania $\mathrm{z}$ alternatywnych możliwości konsumpcji, np. wykorzystywania używanych dóbr (second hand); położenia nacisku na przydatność nabywanych dóbr, a nie na ich ilość; na wymianę dóbr i usług między konsumentami, dzięki której budują oni nowe kanały komunikowania się między sobą; na budowę wspólnot konsumpcyjnych. Ludzie, którzy przyjmują styl życia oparty o dobrowolną prostotę w różnym stopniu angażują się w działania na rzecz ograniczenia konsumpcji. Po pierwsze, ich działania mogą być związane z rezygnacją z niektórych dóbr konsumpcyjnych (np. uznawanych za luksusowe), przy czym utrzymują dotychczasowy konsumpcyjny styl życia. Po drugie, ze znacznym ograniczeniem dotychczasowej konsumpcji i zmianą dotychczasowego stylu życia. Po trzecie, dostosowaniem wzorców życiowych do etosu prostoty. Ludzie przyjmujący tę formę stylu życia przenoszą się z zamożniejszych dzielnic do mniejszych miast, na wieś, do gospodarstw rolnych z zamiarem prowadzenia prostszego życia ${ }^{37}$. Ograniczeniem tego ruchu jest jego stosunkowo niewielki zasięg, obejmujący jedynie kraje wysokorozwinięte, w których najczęściej jego członkami są przedstawiciele klasy średniej i średniej-wyższej ${ }^{38}$. Stosunkowo mniej członków wywodzi się z niższych klas społecznych.

Kolejnym ruchem konsumenckim wartym przybliżenia jest konsumeryzm etyczny propagujący etyczną konsumpcję, w której istotną rolę odgrywa traktowanie zakupu jako wyboru etycznego. Konsumenci związani z tym ruchem próbują uświadomić ludziom globalne konsekwencje nadmiernej konsumpcji, zwrócić uwagę na warunki, w jakich wytwarzane są produkty, na ich skład oraz promować firmy przestrzegające praw człowieka i praw pracowniczych ${ }^{39}$.

W ostatnich latach dynamicznie rozwija się ruch antykonsumpcyjny rozumiany jako wycofanie się z form konsumpcji charakterystycznych dla tzw. zachodniego stylu życia i przyjęcie tych form, które są przyjazne środowisku natural$n^{n e m u}{ }^{40}$. Ruch ten opiera się na założeniu, iż konsumpcjonizm jest zagrożeniem dla duchowości współczesnego człowieka i jego systemu wartości. Formami działania tego ruchu jest, po pierwsze, organizowanie radykalnych bojkotów konsumenckich,

\footnotetext{
${ }^{36}$ P.W. Ballantine, S. Creery, Christ and Consumerism: An Introduction [w:] Christ and Consumerism. Critical reflections on the spirit of our age, red. C. Bartholomew, T. Moritz, Paternoster Publishing, Carlisle 2009, s. 1.

${ }^{37}$ A. Etzoni, Voluntary Simlicity: characterization, select psychological implications and societal consequences, ,Journal of Economic Psychology” 1998, vol. 19, nr 5, s. 620-623.

${ }^{38}$ R.W. Belk, G. Ger, Consumption in Affluent Societies [w:] Encyclopedia on Sustainable Development, red. E.F. Moran, UNESCO 2011, http://www.eolss.net/sample-chapters/c11/e1-11-07-03.pdf (data dostępu: 18.04.2014).

39 A. Lewicka-Strzałecka, Konsumeryzm kontra konsumeryzm, „Annales. Etyka w Życiu Gospodarczym" 2003, vol. 6, s. 136.

${ }^{40}$ I.R. Black, H. Cherrier, Anti-consumption as part of living a sustainability lifestyle: daily practices, contextual motivation and subjective values, ,Journal of Consumer Behavior” 2010, vol. 9, nr 6, s. 467-487.
} 
po drugie, rezygnacja z posiadania dóbr i wycofanie się ze świata konsumpcji i zamieszkiwanie w swoistych komunach, tzw. squatach, które stają się centrami propagującymi styl życia oparty o antykonsumpcję, po trzecie, propagowanie nowych zachowań konsumpcyjnych, np. wytwarzanie we własnym zakresie produktów lub reperacja już posiadanych dóbr, rezygnacja $z$ transportu samochodowego na rzecz poruszania się rowerem, negowanie konsumpcji produktów z żyjących istot, odzyskiwanie produktów wyrzuconych na śmieci (dumpster diving) i pozyskiwanie produktów bez wydatków pieniężnych (shop lifting) ${ }^{41}$.

Skuteczność działań ruchów konsumenckich na rzecz ograniczania konsumpcji zagrażającej środowisku naturalnemu zależy w dużym stopniu od ich form oddziaływania na producentów. Zauważa to Papież Franciszek w encyklice poświęconej problemom ekologicznym, gdzie pisze, że ruchy konsumenckie, którym udaje się sprawić, by nie nabywano niektórych produktów skutecznie wpływają na zmianę funkcjonowania przedsiębiorstw, zmuszając je do rozważenia oddziaływania na środowisko oraz przemyślenia modeli produkcji ${ }^{42}$.

Wszystkie opisane formy dekonsumpcji charakteryzują się dążeniem do racjonalizacji działań ludzi w obszarze konsumpcji. Wspomaga ten proces wzrost świadomości konsumenckiej związanej z postrzeganiem zagrożenia wynikającego z nadmiernej konsumpcji dla środowiska naturalnego, jak i dla trwałych relacji międzyludzkich

\section{Zakończenie}

Refleksja nad współczesną konsumpcją skłania nas do sformułowania wniosku o występowaniu swoistego paradoksu: mianowicie z jednej strony ma miejsce dalsze rozprzestrzenianie się konsumpcjonizmu na nowe obszary życia społecznego np. na religię i tworzenie przyczółków w społeczeństwach biednych, w których wartości konsumpcyjne stają się coraz bardziej atrakcyjne, a z drugiej strony stopniowo rozwija się świadomość ograniczania nadmiernej konsumpcji, co znajduje odbicie w tworzeniu się nowej orientacji, tzw. dekonsumpcji. Jednak pomimo wielu przesłanek świadczących o zmianie poglądów na współczesną konsumpcję nadal najważniejszą orientacją jest konsumpcjonizm, który oferuje miraż szczęścia i przyjemnego życia w świecie konsumpcji. Głównym skutkiem zachowań konsumentów pod wpływem konsumpcjonizmu jest brak umiaru w zakupach, czyli konsumowanie „dla samej konsumpcji”.

Czy zatem jest alternatywa dla stylów życia propagowanych przez konsumpcjonizm? Wydaje się, że może nią być orientacja na zrównoważoną konsumpcję. Wraz ze wzrostem nadmiernej konsumpcji pojawiają się postawy krytyczne wobec

\footnotetext{
${ }^{41}$ L. Portwood-Stacer, Anti-consumption as tactical resistance: Anarchists, subculture, and activist strategy, „Journal of Consumer Culture” 2012, vol. 12, nr 1, s. 92.

${ }^{42}$ Papież Franciszek, Encyklika Laudato SI' Ojca Świętego Franciszka poświęcona trosce o wspólny dom, 2015, s. 164, https://w2.vatican.va/content/dam/francesco/pdf/encyclicals/documents/papa-francesco_20150524_enciclica-laudato-si_pl.pdf (data dostępu: 2015).
} 
konsumpcjonizmu, przejawiające się w dążeniu do umiaru w nabywaniu nowych dóbr i poszukiwaniu oraz spożywaniu produktów, które nie niszczą środowiska naturalnego. Ludzie przejawiający takie postawy za punkt odniesienia przyjmują wartości związane z odpowiedzialnością i sprawiedliwością. Moralność ta wpływa na tworzenie się postawy współodpowiedzialności konsumenta za proces degradacji środowiska naturalnego. Zdecydowane stanowisko zajmuje w tej kwestii nauczanie społeczne Kościoła. Papież Franciszek w encyklice Laudato si' poddaje krytyce nadmierną konsumpcję prowadzącą do degradacji środowiska naturalnego. Uwypukla konieczność przejścia od konsumpcji do poświęcenia, od chciwości do wielkoduszności, od marnotrawstwa do zdolności dzielenia się, do ascezy, która «oznacza uczenie się dawania, a nie po prostu rezygnowania $(. . .)^{43}$. Zatem można oczekiwać wzrostu liczebności tej grupy konsumentów, którzy świadomi szkód, jakie wywiera nadmierna konsumpcja w środowisku naturalnym, zmienią nawyki konsumpcyjne na przyjazne środowisku i innym ludziom.

\section{Bibliografia}

Ballantine P.W., S. Creery, The Consumption and Disposition Behavior of Voluntary Simplifiers, „Journal of Consumer Behavior” 2009, vol. 8, nr 1, s. 45-56.

Bartholomew C., Christ and Consumerism: An Introduction [w:] Christ and Consumerism. Critical reflections on the spirit of our age, red. C. Bartholomew, T. Moritz, Paternoster Publishing, Carlisle 1988.

Bauman Z., Życie na przemiat, Wyd. Literackie, Kraków 2005.

Bauman, Konsumowanie życia, Wyd. Uniwersytetu Jagiellońskiego, Kraków 2009.

Belk, R.W., G. Ger, Consumption in Affluent Societies [w:] Encyclopedia on Sustainable Development, red. E.F. Moran, UNESCO 2011, http://www.eolss.net/sample-chapters/c11/e1-11-07-03.pdf.

Black I.R., H. Cherrier, Anti-consumption as Part of Living a Sustainability Lifestyle: Daily Practices, Contextual Motivation and Subjective Values, ,Journal of Consumer Behavior" 2010, vol. 9, nr 6, s. 467-487.

Bockock R., Consumption, Routledge, London 1993

Bourdieu P., Dystynkacja. Społeczna krytyka władzy sądzenia, Wydawnictwo Naukowe Scholar, Warszawa 2005.

Bylok F., Konsumpcja, konsument i społeczeństwo konsumpcyjne we wspótczesnym społeczeństwie. Studium socjologiczne, Wyd. Naukowe „Sląsk”, Katowice 2013.

Bylok F., Konsumpcja w Polsce i jej przemiany w okresie transformacji, Wyd. Politechniki Częstochowskiej, Częstochowa 2005.

Bywalec Cz., L. Rudnicki, Konsumpcja, PWE, Warszawa 2002.

Campbell C., The Romantic Ethic and the Spirit of Modern Consumerism Basil Blackwell Publisher, London 1987.

${ }^{43}$ Ibidem, s. 9. 
Dąbrowska A., F. Bylok, M. Janoś-Kresło, D. Kiełczewski, I. Ozimek, Kompetencje konsumentów - innowacyjne zachowania, zrównoważona konsumpcja, Wyd. PWE, Warszawa 2015.

Etzioni A., Voluntary Simlicity: Characterization, Select Psychological Implications and Societal Consequences, „Journal of Economic Psychology” 1998, vol. 19, nr 5, s. 619-643.

Ger G., R.W. Belk, I'd Like to Buy the World a Coke: Consumptionscapes of the "Less Affluent World”, „Journal of Consumer Policy” 1996, vol. 19, s. 271-304.

Harrison R, T. Newholm, D. Shaw, Pressure Groups, Campaigns and Consumers [w:] The Ethical Consumer, red. R. Harrison, T. Newholm, D. Shaw, Sage, London 2005.

Haubl R., „Welcome to The Pleasure Dome” Einkaufen als Zeitvertrieb [w:] Freizeit in der Erlebnisgesellschaft. Amüsement zwischen Selbstverwiwklischung und Kommerz, red. H.A. Hartmann, R. Haubl, Auflag 1, Westdeucher Verlag, Wiesbaden 1996.

Hellman K-U., Das konsumistische Syndrom [w:] Räume des Konsums über den Funktionswandel von Räumlichkeit im Zeitalter des Konsumismus, red. K-U. Hellman, G. Zurstiege, VS Verlag für Sozialwissenschaften, Wiesbaden 2008.

Hörning K.H., Ansätze zu einer Konsumsoziologie, Verlag Rombach, Freiburg 1970.

Leibenstein H., Bandwagon, Snob, and Veblen Effects in The Theory of Conspicuous Demand, „Quartely Journal of Economics” 1950, vol. 64, s. 183-207.

Lewicka-Strzałecka A., Konsumeryzm kontra konsumeryzm, „Annales. Etyka w Życiu Gospodarczym" 2003, vol. 6, s. 132-138.

Mc Cracken G., Culture and Consumption. New Approaches to the Symbolic Character of Consumer Goods and Activities, Indiana University Press, Bloomington/Indianapolis 1988.

Miles S., Consumerism - as a Way of Life, Sage, London 1998.

Ottman J.A., Green Marketing: Challenges and Opportunities for the New Marketing Age, NTC Business Books, Lincolnwood 2003.

Papież Franciszek, Encyklika Laudato SI’ Ojca Świętego Franciszka poświęcona trosce o wspólny dom, 2015, https://w2.vatican.va/content/dam/francesco/pdf/encyclicals/do cuments/papa-francesco_20150524_enciclica-laudato-si_pl.pdf.

Portwood-Stacer L., Anti-consumption as tactical resistance: Anarchists, subculture, and activist strategy, „Journal of Consumer Culture” 2012, vol. 12, nr 1, s. 87-105.

Prisching M., Die zweidimensionale Gesellschaft. Ein Essay zur neokonsumistischen Geisteshaltung, VS Verlag für Sozialwisenschaft, Wiesbaden 2009.

Schulze G., Die Erlebnisgesellschaft. Kultursoziologie der Gegenwart, Verlag Campus, Frankfurt/M 1992.

Sklair L. Iconic Architecture and the Culture-ideology of Consumerism, „Theory, Culture \& Society" 2010, vol. 27, nr 5, s. 135-159.

Sklair, L., Sociology of the Global System, Johns Hopkins University Press, Baltimore 1991.

Stihler A., Die Entstehung des modernen Konsums. Darstellung und Erklärungsansätze, Verlag Duncker und Humbold, Berlin 1998.

Szulc E., Dekonsumpcja - moda czy kryzys, seria „Nierówności społeczne a wzrost gospodarczy", nr 24, Uniwersytet Rzeszowski, Rzeszów 2012.

Ullrich W., Habenwollen. Wie funktioniert die Konsumkultur?, S. Fischer Verlag, Frankfurt am Main 2006. 
Veblen Th., Teoria klasy próżniaczej, PWN, Warszawa 1971.

Wątroba W., Homo postmillenius, Wyd. Uniwesytetu Ekonomicznego we Wrocławiu, Wrocław 2008.

Wiswede G., Konsumsoziologie - Eine vergessene Disziplin [w:] Konsum: soziologische, ökonomische und psychologische Perspektiven, red. D. Rosenkranz, Verlag Leske+Budrich, Opladen 2000. 